Gut and Liver, Vol. 12, No. 4, July 2018, pp. 375-384

\title{
Update on the Pathophysiology and Management of Anorectal Disorders
}

\author{
Tanisa Patcharatrakul ${ }^{1,2}$ and Satish S.C. Rao ${ }^{1}$ \\ ${ }^{1}$ Division of Gastroenterology and Hepatology, Department of Internal Medicine, Augusta University, Augusta, GA, USA, and ${ }^{2}$ Division of \\ Gastroenterology, Department of Medicine, King Chulalongkorn Memorial Hospital, Thai Red Cross Society, Bangkok, Thailand
}

Anorectal disorders are common and present with overlapping symptoms. They include several disorders with both structural and functional dysfunction(s). Because symptoms alone are poor predictors of the underlying pathophysiology, a diagnosis should only be made after evaluating symptoms and physiologic and structural abnormalities. A detailed history, a thorough physical and digital rectal examination and a systematic evaluation with high resolution and/or high definition three-dimensional (3D) anorectal manometry, 3D anal ultrasonography, magnetic resonance defecography and neurophysiology tests are essential to correctly identify these conditions. These physiological and imaging tests play a key role in facilitating a precise diagnosis and in providing a better understanding of the pathophysiology and functional anatomy. In turn, this leads to better and more comprehensive management using medical, behavioral and surgical approaches. For example, patients presenting with difficult defecation may demonstrate dyssynergic defecation and will benefit from biofeedback therapy before considering surgical treatment of coexisting anomalies such as rectoceles or intussusception. Similarly, patients with significant rectal prolapse and pelvic floor dysfunction or patients with complex enteroceles and pelvic organ prolapse may benefit from combined behavioral and surgical approaches, including an open, laparoscopic, transabdominal or transanal, and/or robotic-assisted surgery. Here, we provide an update on the pathophysiology, diagnosis, and management of selected common anorectal disorders. (Gut Liver 2018;12:375-384)

Key Words: Rectal diseases; Pelvic floor; Defecation; Constipation

\section{INTRODUCTION}

Anorectal disorders are common and affect about 25\% of the population. ${ }^{1}$ Either structural or functional abnormalities of the anorectum or pelvic floor have been demonstrated in patients with symptoms, such as difficulty defecation, fecal incontinence, rectal bleeding, anorectal pain, and rectal prolapse. Recent advance in diagnostic techniques, particularly the advent of high resolution and high definition anorectal manometry, ultrasound, and defecography have provided much better delineation of the anatomical changes and phenotypes, as well as a better understanding of the pathophysiology of these disorders, often leading to improve treatments.

\section{NORMAL ANATOMY AND PHYSIOLOGY OF PELVIC FLOOR}

A working knowledge of the normal defecation and continence mechanism(s) is important. These key processes are dependent on the anatomical integrity and synchronized interaction between the pelvic floor muscles, and the nervous system. The deep pelvic muscles, also known as levator ani, is a complex unit that consists of several muscle components: pubococcygeus, ileococcygeus, and puborectalis. These muscles play an important role in supporting the pelvic organs. The normal baseline activity of the levator muscle draws the distal parts of the urethra, vagina, and rectum toward the pubic bones. This function maintains anorectal angulation and creates a mechanical barrier for the flow of stool and maintenance of continence mechanism. ${ }^{2}$ The superficial layers of pelvic floor include the internal anal sphincter (IAS) and external anal sphincter, and connective tissue. These superficial layers are largely responsible for controlling the evacuation of stool from the rectal vault. ${ }^{2}$ During normal defecation, the voluntary effort of bearing down increases the intra-abdominal pressure, together with the con-

Correspondence to: Satish S.C. Rao

Division of Gastroenterology and Hepatology, Department of Internal Medicine, Augusta University, AD 2238, Digestive Health Center, 1481 LaneyWalker Blvd, Augusta, GA 30912, USA

Tel: +1-706-721-2238, Fax: +1-706-721-0331, E-mail: srao@augusta.edu

Received on April 7, 2017. Revised on June 5, 2017. Accepted on June 10, 2017. Published online October 23, 2017

pISSN 1976-2283 eISSN 2005-1212 https://doi.org/10.5009/gnl17172

@ This is an Open Access article distributed under the terms of the Creative Commons Attribution Non-Commercial License (http://creativecommons.org/licenses/by-nc/4.0) which permits unrestricted non-commercial use, distribution, and reproduction in any medium, provided the original work is properly cited. 
traction of the rectum and perineal muscles. Simultaneously, the anal sphincters and puborectalis relax, the anorectal angle widens, and the perineum descends. These sequential movements facilitate the movement of stool from the rectum resulting in stool evacuation. The pelvic floor receives nerve supply from branches from the sacral nerve roots of S2, S3, and S4, the pudendal nerve, perineal nerves, and the sympathetic and parasympathetic nerves. The incoordination of the pelvic floor muscles can lead to defecation disorders, and weakness or damage to these muscles and nerves leads to fecal incontinence. Likewise, dysfunction of the pelvic floor nerves may cause rectal hyposensitivity and abnormal motor control leading to fecal incontinence, constipation, or rectal pain.

\section{GENERAL CLINICAL EVALUATION: DIGITAL RECTAL EXAMINATION}

A digital rectal examination (DRE) combined with a vaginal examination when appropriate is an essential component of the clinical evaluation. Anorectal inspection can reveal skin excoriation or irritation from fecal soiling. Assessment of perineal sensation and anocutaneous reflex by gently stroking the perianal skin with a cotton swab or blunt needle in all four quadrants will elicit reflex contraction of the external anal sphincter. If this is absent, a neuropathy should be suspected. DRE may reveal a stricture, spasm, tenderness, mass, blood or stool. If stool is present, its consistency should be noted and the patient should be asked if they were aware of its presence. A lack of awareness of stool in the rectum may suggest rectal hyposensitivity. It is useful to assess the resting and squeeze tone of the anal sphincter and puborectalis muscle by asking the subject to squeeze. More importantly, the subject should be asked to push and bear down as if to defecate. During this maneuver, the examiner should perceive relaxation of the external anal sphincter and/or the puborectalis muscle, together with perineal descent. A hand placed on the abdomen can gauge the abdominal pushing effort. An absence of these normal mechanics should raise the index of suspicion for dyssynergic defecation. ${ }^{3}$ DRE has a sensitivity of $75 \%$ and specificity of $87 \%$ for identifying dyssynergia. ${ }^{3}$ Examination during straining or bimanual rectal and vaginal examination can further help to confirm or facilitate diagnosis of rectocele and rectal prolapse. Even though DRE is a useful clinical tool, there is a lack of knowledge on how to perform a comprehensive evaluation. ${ }^{4}$ A survey of 256 final year medical students revealed that $17 \%$ had never performed a DRE and 48\% were unsure of giving an opinion based on their findings. Thus training on how to perform a proper DRE is urgently needed.

\section{DYSSYNERGIC DEFECATION}

Constipation secondary to dyssynergic defecation is common with a prevalence of $27 \%$ to $59 \% .^{5-7}$ It carries a significant impact on quality of life. ${ }^{8,9}$ Dyssynergic defecation is primarily due to the inability to coordinate the abdominal, and pelvic floor muscles to evacuate stools. ${ }^{10}$ This failure of rectoanal coordination consists of inadequate propulsive force, paradoxical anal sphincter contraction or inadequate anal sphincter relaxation. ${ }^{10}$ Recently, a large controlled study showed that three phenotypes; high anal sphincter pressure at rest and during defecation, inadequate propulsive force, and hybrid of both disturbance can discriminate among patients with normal and abnormal balloon expulsion time and these phenotypes were uncorrelated. ${ }^{11}$ This suggests that the pathophysiology of dyssynergic defecation and inadequate propulsive force may be distinct. How, when and why an individual develops this condition is unclear. A prospective survey of 118 patients with dyssynergic defecation suggested that the problem began during childhood in 31\% of patients, and after a particular event, such as, pregnancy, trauma or back injury in $29 \%$ of patients, and there were no identifiable precipitating cause in $40 \%$ of patients. ${ }^{8}$ Almost $60 \%$ of patients reported frequent or intermittent passage of hard stool. Thus, excessive straining to expel hard stools, over time, may also lead to this behavioral problem.

\section{Diagnosis}

The first step in making a diagnosis of dyssynergic defecation is to exclude any metabolic or structural abnormalities. Differential diagnosis includes many structural or functional abnormalities that may also lead to an evacuation disorder, although these conditions may coexist, such as, rectocele, anorectal neoplasia, rectal prolapse, excessive perineal descent, and mucosal intussusception. These conditions can be readily identified through careful physical exam and appropriate tests.

\section{1) Anorectal manometry}

Anorectal manometry provides a comprehensive assessment of pressure activity in the rectum and anal sphincter region together with an assessment of rectal sensation, rectoanal reflexes and rectal compliance. ${ }^{12}$ Normally, when a subject bears down or attempts to defecate, there is a rise in rectal pressure, and simultaneously there is relaxation or decrease of the external anal sphincter pressure. The inability to perform this coordinated movement either due to impaired rectal contraction, paradoxical anal contraction or impaired anal relaxation or a combination of these mechanisms represents the key abnormality in patients with dyssynergic defecation. Based on these features at least four types of dyssynergia have been recognized (Fig. 1).

Four additional subtypes were described recently by using high resolution manometry catheter which provides greater of resolution of anal sphincter and puborectalis morphology, ${ }^{13}$ and this needs further confirmation.

During anorectal manometry, when a subject is bearing down it is possible to measure the intrarectal pressure, anal residual 
Type I

The patient can generate an adequate pushing force (rise in intra-abdominal pressure) along with a paradoxical increase in anal sphincter pressure.

Type II

The patient is unable to generate an adequate pushing force (no increase in intrarectal pressure) but can exhibit a paradoxical anal contraction.

\section{Type III}

The patient can generate an adequate pushing force (increase in intrarectal pressure) but, either has absent or incomplete $(<20 \%)$

sphincter relaxation (i.e., no decrease in anal sphincter pressure).

\section{Type IV}

The patient is unable to generate an adequate pushing force and demonstrates an absent or incomplete anal sphincter relaxation.
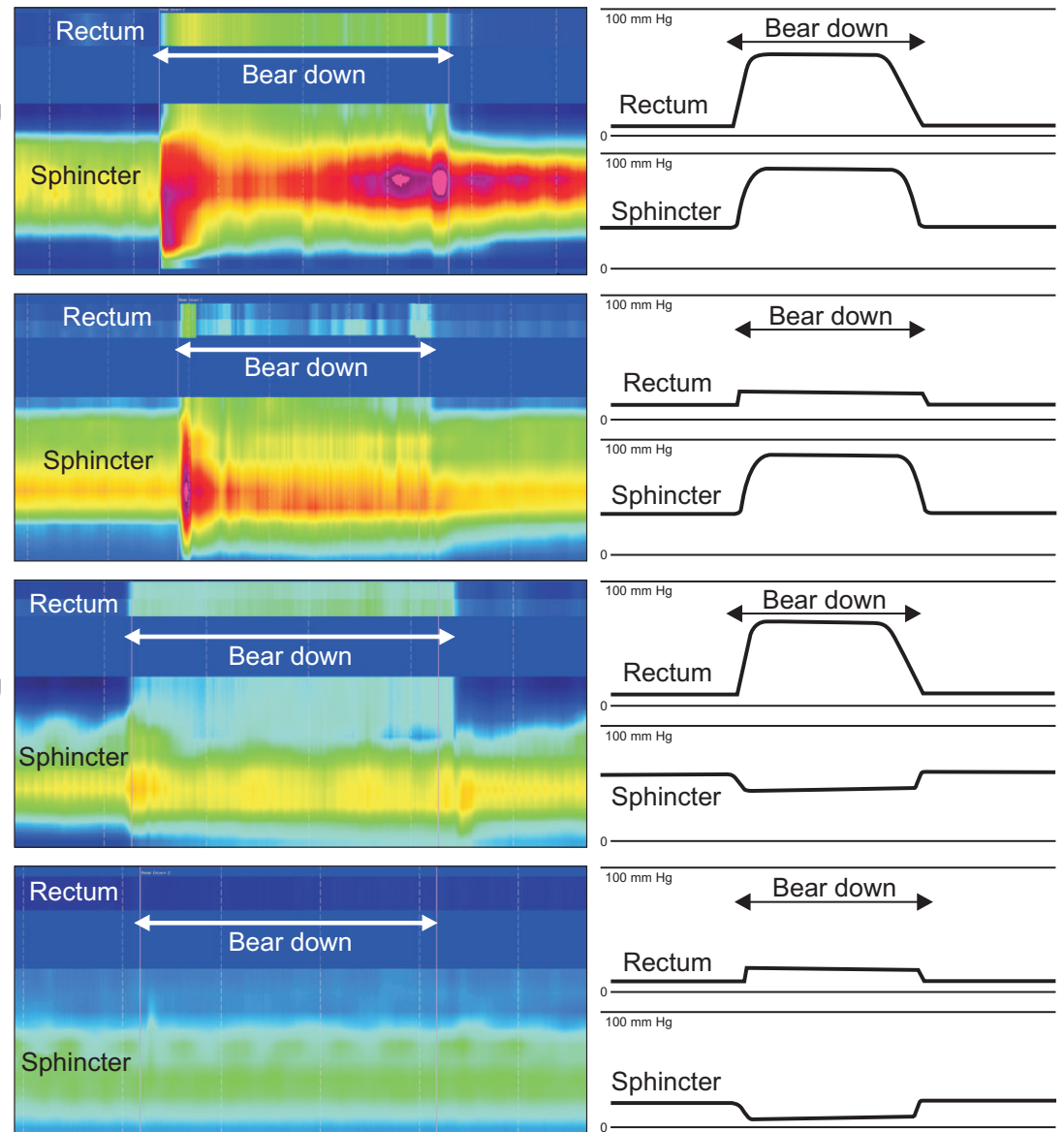

Sphincter

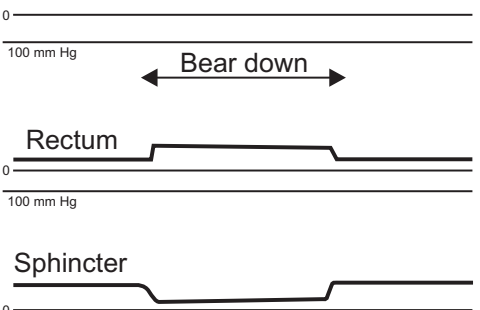

Fig. 1. High definition 3-dimensional manometry, high resolution manometry, and conventional manometry findings for each dyssynergic defecation type.

pressure and the percentage of anal relaxation. ${ }^{10}$ From these measurements, it is possible to derive an index of the forces required to perform defecation-the defecation index which is defined as a ratio of intrarectal pressure/anal residual pressure. ${ }^{10}$ The defecation index may serve as a simple and useful quantitative measure of the rectoanal coordination during defecation. In addition to the motor abnormalities, sensory dysfunction may also be present. Both the first sensation and the threshold for a desire to defecate may be higher in about $60 \%$ of patients with dyssynergic defecation. ${ }^{10}$ This may also be associated with an increased rectal compliance or rectal hyposensitivity.

Although the dyssynergia patterns are reproducible ${ }^{12}$ and has high interobserver agreement rate for identifying these abnormalities especially for type I and IV, ${ }^{14}$ studies show that these dyssynergic patterns were also observed in nearly 90\% of asymptomatic controls and patients with chronic proctalgia without constipation. ${ }^{14,15}$ These findings are partly explained by the non-physiologic nature of defecation assessment, i.e., in the left lateral position ${ }^{16}$ and with an empty rectum. In contrast, this pattern may be corrected in many by adopting a more physiologic process. In one study, coaching about the defecatory process during attempted defecation changed manometric findings from locally validated "pathologic" to "normal" values in 12/39 with dyssynergic defecation. ${ }^{17}$ The prevalence of findings suggestive of abnormal defecation ranged from 14.9\% for absent opening of the anorectal angle on defecography to 47\% for a dyssynergic pattern with manometry and 52.9\% for a dyssynergic pattern with ultrasonography. ${ }^{18}$ Thus, not only manometry but combined abnormalities in diagnosing modalities (i.e., balloon expulsion, manometry, and imaging) are required for making diagnosis of this condition (see diagnostic criteria below).

\section{2) Balloon expulsion test}

In this test, a 4-cm long balloon filled with $50 \mathrm{~mL}$ of warm water is placed in the rectum. ${ }^{19}$ After placement, the patient is given privacy and asked to expel the balloon. A stop watch is provided to assess the time required for expulsion. Normal individuals can usually expel a balloon within one minute with this technique. ${ }^{19}$ However, the normal values of balloon expulsion time depend on different techniques, body positions and types of balloons. ${ }^{20}$ Balloon expulsion is a useful screening test for identifying patients with dyssynergic defecation because of high specificity (80\% to $90 \%$ ), although the sensitivity is low $50 \%$. $^{20,21}$ 


\section{3) Defecography and magnetic resonance defecography}

Defecography is a dynamic fluoroscopy study performed in the sitting position. After placing $150 \mathrm{~mL}$ of barium paste into the patient's rectum, the patient is asked to squeeze and to evacuate the barium. This test provides useful information particularly on the structural changes, such as, rectocele, rectal prolapse, descending perineal syndrome and intussusception that may coexist with dyssynergic defecation. ${ }^{22}$

Magnetic resonance (MR) defecography or dynamic pelvic magnetic resonance imaging (MRI) can evaluate pelvic floor anatomy, dynamic motion, and rectal evacuation simultaneously. It provides an excellent resolution of anal sphincters, levator ani muscles and soft tissue surrounding the rectum without radiation exposure. ${ }^{23}$ Limitations include its high cost, lack of availability, and possible low sensitivity to detect rectal intussusception because it is more difficult to evacuate the contrast compared to barium defecography. ${ }^{23}$

Defecography or MR defecography are often used as adjunct tests when anorectal manometry and balloon expulsion tests are equivocal, or in patients with normal manometry but with prolonged balloon expulsion times. ${ }^{24}$ The strengths, weaknesses, and cost comparisons between anorectal manometry, balloon expulsion test, defecography, and MR defecography for establishing a diagnosis of dyssynergic defecation are shown in Table 1.

\section{4) Colonic transit study}

Colonic transit time can be measured by obtaining abdominal radiographs after patients ingest radio-opaque markers, ${ }^{25}$ a wireless motility capsule (WMC), ${ }^{26}$ or by scintigraphy. ${ }^{27}$ The WMC and scintigraphy can also measure gastric emptying and small intestinal transit, which may also be delayed in constipated patients. ${ }^{28}$ There is good diagnostic agreement between the WMC and radio-opaque markers technique.

Up to two-thirds of patients with a defecation disorder also have delayed colonic transit. ${ }^{8}$ Although, slow transit constipation may coexist with dyssynergic defecation, a study in patients with both dyssynergia and slow colonic transit showed that colonic transit improved after dyssynergia treatment with biofeedback therapy. ${ }^{12}$ This suggests that outlet dysfunction is responsible for delayed colonic transit. Therefore, evaluation and treatment for dyssynergic defecation is recommended first in patients with chronic constipation, and further colonic or whole gut study is recommended if patients fail biofeedback therapy. ${ }^{24}$

\section{5) Diagnostic criteria for dyssynergic defecation}

Diagnosis of dyssynergic defecation requires three components: first, symptoms of constipation; second, manometric or electromyography evidence of dyssynergic pattern during attempted defecation; and third, one other abnormal colorectal

Table 1. Strengths, Weaknesses, and Cost Comparisons between Tests Commonly Used for the Diagnosis of Dyssynergic Defecation

\begin{tabular}{lccc}
\hline & \multicolumn{2}{c}{ Strength } & \\
\cline { 2 - 3 } & $\begin{array}{c}\text { Anorectal anatomy } \\
\text { assessment }\end{array}$ & $\begin{array}{c}\text { Anorectal function } \\
\text { assessment }\end{array}$ & Weakness \\
\hline Anorectal manometry & + & +++ & Need normal values for sitting position test \\
Balloon expulsion test & - & + & Low sensitivity \\
Defecography & ++ & ++ & Radiation exposure \\
MR defecography & +++ & ++ & Not a physiologic position \\
\hline
\end{tabular}

MR, magnetic resonance.

Table 2. Rome IV Diagnostic Criteria for Functional Defecation Disorders

1. The patient must satisfy diagnostic criteria for functional constipation and/or irritable bowel syndrome with constipation

2. During repeated attempts to defecate, there must be features of impaired evacuation, as demonstrated by two of the following* three tests:

a. Abnormal balloon expulsion test

b. Abnormal anorectal evacuation pattern with manometry or anal surface electromyography

c. Impaired rectal evacuation by imaging

Subcategories a and b apply to patients who satisfy criteria for functional defecation disorders

a. Diagnostic criteria for inadequate defecatory propulsion: inadequate propulsive forces as measured with manometry with or without inappropriate contraction of the anal sphincter and/or pelvic floor muscles ${ }^{\dagger}$

b. Diagnostic criteria for dyssynergic defecation: inappropriate contraction of the pelvic floor as measured with anal surface electromyography or manometry with adequate propulsive forces during attempted defecation ${ }^{\dagger}$

EMG, electromyography.

${ }^{*}$ Criteria fulfilled for the last 3 months with symptom onset at least 6 months before diagnosis; ${ }^{\dagger}$ These criteria are defined by age- and sex-appropriate normal values for the technique. 
test such as the balloon expulsion test, defecography, or marker retention with colonic transit study. The current Rome IV diagnostic criteria includes inadequate defecatory propulsion as another cause of a defecation disorder besides dyssynergic defecaton. ${ }^{29}$ A study showed that patients with inadequate defecatory propulsion or who cannot appropriately increase propulsive forces with or without contraction or less than 20\% relaxation of anal sphincter during attempted defecation, demonstrated prolonged rectal balloon evacuation time and decreased pelvic floor descent on defecography. ${ }^{30}$ Although patients with constipation-predominant irritable bowel syndrome (IBS) are not eligible to be diagnosed with defecatory disorders per Rome III diagnostic criteria. However, an association between IBS and defecation disorders has been recognized and can be effectively treated with biofeedback therapy irrespective of coexistent IBS. $^{7,31}$ So, the current Rome IV diagnostic criteria ${ }^{29}$ includes IBS with constipation patients in a new diagnostic criteria of functional defecation disorders (Table 2).

\section{Treatment}

The strength of current evidence and as endorsed by American and European Societies of Neurogastroenterology \& Motility support the use of biofeedback as a specific treatment for dyssynergic defecation. ${ }^{32}$ The treatment goals are to correct the incoordination of abdominal and pelvic floor muscles during evacuation and to improve perception of rectal filling in patients with impaired rectal sensation. Randomized controlled trails have shown that it is efficacious in up to 70\% and superior to other modalities including sham therapy and laxatives ${ }^{33-35}$ and a long-term study showed long-term benefits for more than 2 years. ${ }^{36}$ Because it is a labor intensive treatment and requires 4-6 sessions, the success of biofeedback therapy depends on both the patient's motivation and the skill of the biofeedback therapist. There are limited studies determining the predictive factors for biofeedback therapy response and these studies used different biofeedback technique and treatment outcome measurement. ${ }^{13}$ Demographic features, overlapping IBS, and prolonged balloon expulsion time were not associated with poor biofeedback therapy response whereas symptom severity, use of digital maneuver, presence of abnormal rectal sensation, and presence of delayed colonic transit showed conflicting results. ${ }^{13}$

\section{RECTAL PROLAPSE}

The evolution of rectal prolapse starts from excessive straining over time leading to the laxity or weakness of pelvic floor muscles. Over time this leads to connective tissue injury including nerve injury and neuropathy of the pelvic floor with loss of counter-acting resistive force during defecation, thereby leading to rectal intussusception initially, followed by external mucosal prolapse, and eventually a full protrusion of all layers of the rectal wall through the anus. ${ }^{37}$ Most patients with rectal prolapse present with anal protrusion, rectal pain, bloody or mucous passage, symptoms of fecal incontinence or obstructed defecation. In severe cases, the large mass cannot reduce spontaneously, and may become incarcerated or strangulatied. ${ }^{38}$

Both complete rectal prolapse and internal intussusception can occur independently or can be associated with the descent of other pelvic organs, e.g., uterine or vaginal vault prolapse. Pre-existing dyssynergic defecation that cause chronic excessive straining may coexist. ${ }^{37}$

\section{Diagnosis}

Anal inspection may reveal normal anal area, skin excoriation or irritation but when patient bears down in a sitting position, the patulous anus and prolapsed rectum can become visible. Rectal mucosa is often edematous and sometimes friable with ulcerated mucosa. Rectal prolapse is graded into four types: grade 1, up to anal verge; grade 2, prolapse outside the anus but reduces spontaneously; grade 3, prolapses outside the anus but can be manually reduced; and grade 4, prolapse cannot be reduced manually.

Colonoscopy is useful to rule out the presence of a lead point (e.g., mass) or other pathology that cause rectal bleeding and rule out prolapsing internal hemorrhoids. Anorectal manometry may reveal low resting sphincter pressure especially in patients with complete rectal prolapse, which predicts poor postoperative continence. $^{39}$ Rectal sensation and compliance may be impaired. Defecography, which is performed in a sitting position usually aids diagnosis in patients who report prolapse, but have normal physical examination in lateral position. MR defecography may reveal other anatomical defects and other associated pelvic organ prolapse that can aid in assessment of surgical intervention. ${ }^{40}$ Three-dimensional (3D)-endoanal ultrasonography may show asymmetry, sphincter defects and thickening of the IAS and submucosa. Demonstration of anal sphincter defect is useful when considering sphincter reconstruction. ${ }^{41}$

\section{Management}

Patients with grade 1 to 2 prolapse without symptoms related to the prolapse do not require surgery. Patients should be advised to keep their stools soft and treat the associated conditions such as dyssynergic defecation and avoid excessive straining. However, symptomatic grade 3 to 4 prolapse requires surgery. There are multiple surgical options, and both abdominal and perineal approaches are available. The surgical approach should be individualized base on each patient's symptoms, bowel habits, anatomy, and co-morbidity. The abdominal approach allows the surgeon to deal with factors that are associated with rectal prolapse including a deep cul-de-sac of the pouch of Douglas, lack of sacral fixation, and redundancy of the sigmoid colon. ${ }^{37}$ Resection of sigmoid colon is preferably performed in patients with significant redundancy, but should be avoided in patients with the combination of diarrhea and/or incontinence as these 
symptoms may worsen with resection. ${ }^{37}$ The perineal approach has a lower perioperative morbidity and reserve for elderly patients, patients with significant co-morbid illness, or those who have previous extensive pelvic surgery. ${ }^{38}$ Overall, existing data demonstrate no differences in recurrence rates comparing abdominal and perineal approaches, although there appears to be a trend toward improved continence with abdominal techniques. ${ }^{42}$ Recent studies have shown that laparoscopic and robotic colorectal resection are a safe and feasible option; however, more studies are required. ${ }^{43}$

\section{RECTOCELE}

Rectocele is an outpouching of the rectal wall through a weakened rectovaginal septum (anterior) and rarely towards the sacrum (posterior). Rectocele is common in women with certain risk factors including aging, obesity, obstetric injury, multiple vaginal deliveries, and presence of dyssynergic defecation had been proposed. ${ }^{44}$ Many of these risk factors can be interconnected and are additive in their effects, such as, underlying obstetric injury couples with age-related degeneration of connective tissue, and chronic increase in intra-abdominal pressure from obesity, or frequent straining can compound the damage. Recent study using 3D MRI characterized the structural deformations of the posterior vaginal wall in women with rectocele. ${ }^{45}$ They demonstrated a consistent downward displacement of the upper two-thirds of the vagina as well as a folding of the posterior vaginal wall. As prior imaging of rectoceles has focused almost entirely on the anterior wall of the rectum, better characterization of the movements of the vagina itself may help explain some of the divergent symptoms among patients with rectocele. Asymptomatic rectocele had been reported in 45\% of healthy subjects $^{46}$ but symptoms such as a feeling of incomplete evacuation, prolonged straining, sensation of blockage or inability to evacuate, fecal soiling, dyspareunia, anorectal/vaginal pain, and urologic symptoms can be reported. ${ }^{47}$ However, caution must be exercised before attributing these symptoms to just an obvious bulge because it seems to have little clinical correlation with the size of the rectocele. ${ }^{48}$

\section{Diagnosis}

Defecography is considered to be the gold standard for diagnosis of rectocele. It can measure rectocele size, quantify stool retention and also provides information regarding coexisting conditions such as rectal mucosal intussusception or excessive perineal descent. ${ }^{49}$ MRI provides good visualization of the rectocele, and dynamic MRI can correlate with pelvic floor movements. Images during the defecation phase can identify abnormal pelvic organs descent which was found to be associated with a presence of large rectocele. ${ }^{50}$ Rectocele may be associated with dyssynergic defecation. However, most of the patients with rectocele had normal balloon expulsion time..$^{50}$ High resting anal sphincter pressure had been reported, but rectal sensation and rectal compliance are usually normal and there are no specific anorectal manometric findings for a rectocele..$^{50,51}$

\section{Management}

Clinical correlation is essential before labeling a rectocele as clinically significant. Although rectoceles $>3 \mathrm{~cm}$ with retention of barium or stool is generally considered to be clinically significant and surgical repair improves symptoms in a majority of patients, the symptom improvement was poorly correlated with the postoperative dimensions of the rectocele. ${ }^{48}$ Thus, the first approach is to treat any underlying or coexisting defecation disorders or urogynecological disorders if it is presence and that might relate to the patient symptoms. In patients seeking relief from difficulty defecation who are noted to have a rectocele, a more thorough investigation particularly to exclude dyssynergic defecation is warranted before simply offering surgical repair of rectocele. Even if the primary problem is vaginal symptoms, investigation of bowel function is indicated because chronic constipation, even if unrelated to the rectocele, may predispose to recurrence of the prolapse. In general, surgery is appropriate for symptomatic patients with large rectocele $(>3 \mathrm{~cm})$ who fail conservative treatment or those with coexisting symptomatic pelvic organ prolapse. ${ }^{52}$ The technical goal of preventing the rectum from bulging into the posterior vaginal wall can be accomplished by either strengthening the posterior wall of the vagina (by plicating it in the midline, repairing defects in it, or resuspending it from the sacrum) or reinforcing the front wall of the rectum (also by plication or ventral suspension). Another approach is the interposition of tissue or a graft between the two structures. Recently, partial resection of the rectal wall has been advocated as another method of reinforcing the anterior rectal wall and decreasing redundancy. ${ }^{47}$

\section{DESCENDING PERINEUM SYNDROME}

Descending perineum syndrome is characterized by the bulging and excessive descent of the perineum during defecation, often with a weak pelvic floor, and can be demonstrated with either physical examination or defecography. Typically, patients present with a long history of chronic straining and a sensation of incomplete evacuation followed by a sensation of obstruction. Over time, complaints of mucoid discharge, bleeding, and perineal irritation may occur due to the prolapse of the anterior rectal wall. ${ }^{53,54}$ It is best described as a vicious cycle of straining and constipation, which leads to more straining and exacerbation of the anatomical abnormality and descent of the perineum. Studies have demonstrated an association with pudendal neuropathy but studies were conflicting regarding the correlation between degree of descent and severity of neuropathy. ${ }^{55-57}$ 


\section{Diagnosis}

The precise definition of descending perineum syndrome varies as an overlap of normal and abnormal values. Defecography revealing perineal descent of $>3 \mathrm{~cm}$ on straining, as measured from resting, is highly suggestive of a weakened perineum. This descent can be termed increased dynamic perineal descent, which can be compared to increased fixed perineal descent when there is a $4-\mathrm{cm}$ descent at rest. ${ }^{54} \mathrm{MR}$ defecography also allows for better delineation of the soft tissue structures of multiple compartments of the pelvis, allowing for a broader overview of other potential pelvic floor defects, which is useful for preoperative evaluation and can increase the rate of successful surgical outcomes. Studies that compared conventional defecography with MR defecography for the diagnosis of perineal descent suggest that it is better seen in the sitting position compared with the supine position. ${ }^{58,59}$ However, factors include how test is ordered, whether it includes evacuation phase, and the nature of rectal contrast that may each determine its sensitivity.

\section{Management}

Treatment consists of mainly correcting the excessive straining or dyssynergic defecation when it coexists with biofeedback therapy. Although not Food and Drug Administration (FDA)approved, specialized commode seats and use of an artificial device-a polycarbonate plate with two separate holes for passing urine and stool and a built in hump which supports the perineum when sitting on a commode are available and have been suggested as ways to potentially alleviating symptoms. ${ }^{60}$ The device together with biofeedback therapy may improve symptoms in about $50 \% .^{52}$ At present, there is no consensus on a surgical procedure for the treatment of descending perineum syndrome. Abdominal sacrocolpoperineopexy and obliteration of the posterior cul-de-sac, transvaginal reconstruction and anchoring of perineal body, and transanal stapling procedure have all been reported but their usefulness is limited by the small sample size. ${ }^{60}$

\section{SOLITARY RECTAL ULCER SYNDROME}

Solitary rectal ulcer syndrome (SRUS) is characterized by either erythema or ulceration in the rectum. It is not necessarily solitary or ulcerated as multiple ulcers can be found in 30\% of patients. ${ }^{61}$ It occurs commonly in the third or fourth decade with a slightly higher prevalence in females. ${ }^{62}$ The most accepted pathophysiology of SRUS is either direct trauma or local ischemia to the rectal mucosa. Ulceration is thought to occur during repeated forceful straining against an immobile pelvic floor leading to mucosal prolapse and/or direct trauma from digital manipulations. This may lead to venous congestion, poor blood flow, and edema in the rectal mucosa and ischemic changes with resulting in ulceration. ${ }^{63}$ Patients usually present with rec- tal bleeding, tenesmus, mucus discharge, straining, and a feeling of incomplete evacuation. Majority use digital maneuvers but rarely admit. About 20\% to 40\% have diarrhea, and 25\% are misdiagnosed or treated as inflammatory bowel disease. In some patients, an underlying psychologic disorder, such as obsessive compulsive disorder may be present. ${ }^{61}$ Anorectal manometry studies demonstrated dyssynergic defecation together with delayed balloon expulsion time in 25\% to $82 \%$ of patients with SRUS. ${ }^{63}$ Also, SRUS patients exhibited rectal hypersensitivity, high anal pressure and paradoxical puborectalis contraction during straining. ${ }^{64,65}$

\section{Diagnosis}

The appearances of SRUS on endoscopy may vary from hyperemic changes to established ulcers on the anterior or anterolateral wall of the rectum at about 5 to $10 \mathrm{~cm}$ from anal verge. Lesions are usually shallow, 1 to $1.5 \mathrm{~cm}$ in size, and covered by a white, grey or yellowish slough. ${ }^{61}$ The adjacent mucosa may appear nodular, lumpy or granular. ${ }^{66}$ The lesions can be multiple (30\%), ulcerated (57\%), polypoid (25\%) or with patches of hyperemic mucosa (18\%). ${ }^{63}$ Biopsy confirmation is important and key histological features include fibromuscular proliferation of the lamina propria, hypertrophied muscularis mucosa with extension of muscle fibers upwards between the crypts, and glandular crypt abnormalities. ${ }^{67}$ Presence of diffuse collagen deposition in the lamina propria is a sensitive marker for differentiating SRUS from inflammatory bowel disease. ${ }^{68}$ Defecography may show other abnormalities such as rectal mucosal intussusception in $45 \%$ to $80 \%$ of subjects. Endoanal ultrasonography may show marked thickening of the IAS which is highly suggestive of coexisting high grade rectal intussusception. ${ }^{69}$

\section{Management}

Although randomized controlled trials are scarce, behavioral therapy that includes refraining from using digital maneuvers together with biofeedback therapy remain the mainstay of treatment. This treatment combination improved symptoms including straining, and bleeding in 56\% to $67 \%$ of patients with significant sigmoidoscopic improvement in 30\% to 55\%. An increase in rectal blood flow also demonstrated after biofeedback therapy. ${ }^{63,70}$

Topical treatments, including sucralfate, salicylate, corticosteroids, sulfasalazine, mesalazine and topical fibrin sealant, have been reported to be effective in uncontrolled studies. ${ }^{62}$ A recent randomized controlled study suggests that argon plasma coagulation may be useful in controlling bleeding and improving healing of ulcers better than a standard of care. ${ }^{71}$

Rectopexy with or without anterior resection should be performed in highly selected cases with an advanced grade of rectal intussusception and rectal prolapse. A study of 48 patients who underwent laparoscopic ventral mesh rectopexy after biofeedback therapy reported sustained improvement in quality of 
life and bowel symptoms score at 2 years in the 52\% who were followed up for 3 to 15 years. $^{72}$

\section{CONCLUSIONS}

Anorectal disorders present with a variety of symptoms and result from either structural or functional dysfunction. Clinical correlation is essential before labeling an abnormal finding as clinically significant. Together with a detailed history, a thorough physical and DRE and appropriate testing, in most patients the underlying cause and type of anorectal disorder can be correctly identified and treatment can be tailored. In patients with constipation and dyssynergic defecation, biofeedback therapy should be offered and surgery avoided. Likewise, biofeedback therapy can be useful in SRUS, excessive perineal descent, often because of coexisting dyssynergia. Several surgical approaches including open, laparoscopic, transabdominal approach, transanal approach, and robotic assisted surgery have been advocated and appear to be useful but only in selected cases and randomized trials are lacking.

\section{CONFLICTS OF INTEREST}

No potential conflict of interest relevant to this article was reported.

\section{REFERENCES}

1. Wu JM, Vaughan CP, Goode PS, et al. Prevalence and trends of symptomatic pelvic floor disorders in U.S. women. Obstet Gynecol 2014;123:141-148.

2. Raizada V, Bhargava V, Karsten A, Mittal RK. Functional morphology of anal sphincter complex unveiled by high definition anal manometery and three dimensional ultrasound imaging. Neurogastroenterol Motil 2011;23:1013-1019.e460.

3. Tantiphlachiva K, Rao P, Attaluri A, Rao SS. Digital rectal examination is a useful tool for identifying patients with dyssynergia. Clin Gastroenterol Hepatol 2010;8:955-960.

4. Wong RK, Drossman DA, Bharucha AE, et al. The digital rectal examination: a multicenter survey of physicians' and students' perceptions and practice patterns. Am J Gastroenterol 2012;107: 1157-1163.

5. Mertz H, Naliboff B, Mayer E. Physiology of refractory chronic constipation. Am J Gastroenterol 1999;94:609-615.

6. Nyam DC, Pemberton JH, Ilstrup DM, Rath DM. Long-term results of surgery for chronic constipation. Dis Colon Rectum 1997;40:273-279.

7. Patcharatrakul T, Gonlachanvit S. Outcome of biofeedback therapy in dyssynergic defecation patients with and without irritable bowel syndrome. J Clin Gastroenterol 2011;45:593-598.

8. Rao SS, Tuteja AK, Vellema T, Kempf J, Stessman M. Dyssynergic defecation: demographics, symptoms, stool patterns, and quality of life. J Clin Gastroenterol 2004;38:680-685.

9. Rao SS, Seaton K, Miller MJ, et al. Psychological profiles and quality of life differ between patients with dyssynergia and those with slow transit constipation. J Psychosom Res 2007;63:441-449.

10. Rao SS, Welcher KD, Leistikow JS. Obstructive defecation: a failure of rectoanal coordination. Am J Gastroenterol 1998;93:10421050.

11. Ratuapli SK, Bharucha AE, Noelting J, Harvey DM, Zinsmeister AR. Phenotypic identification and classification of functional defecatory disorders using high-resolution anorectal manometry. Gastroenterology 2013;144:314-322.e2.

12. Rao SS, Mudipalli RS, Stessman M, Zimmerman B. Investigation of the utility of colorectal function tests and Rome II criteria in dyssynergic defecation (Anismus). Neurogastroenterol Motil 2004;16:589-596.

13. Rao SS, Patcharatrakul T. Diagnosis and treatment of dyssynergic defecation. J Neurogastroenterol Motil 2016;22:423-435.

14. Grossi U, Carrington EV, Bharucha AE, Horrocks EJ, Scott SM, Knowles CH. Diagnostic accuracy study of anorectal manometry for diagnosis of dyssynergic defecation. Gut 2016;65:447-455.

15. Chiarioni G, Nardo A, Vantini I, Romito A, Whitehead WE. Biofeedback is superior to electrogalvanic stimulation and massage for treatment of levator ani syndrome. Gastroenterology 2010;138: 1321-1329.

16. Rao SS, Kavlock R, Rao S. Influence of body position and stool characteristics on defecation in humans. Am J Gastroenterol 2006; 101:2790-2796.

17. Heinrich H, Fruehauf H, Sauter M, et al. The effect of standard compared to enhanced instruction and verbal feedback on anorectal manometry measurements. Neurogastroenterol Motil 2013;25: 230-237.e163.

18. Videlock EJ, Lembo A, Cremonini F. Diagnostic testing for dyssynergic defecation in chronic constipation: meta-analysis. Neurogastroenterol Motil 2013;25:509-520.

19. Remes-Troche JM, Rao SS. Diagnostic testing in patients with chronic constipation. Curr Gastroenterol Rep 2006;8:416-424.

20. Rao SS, Ozturk R, Laine L. Clinical utility of diagnostic tests for constipation in adults: a systematic review. Am J Gastroenterol 2005;100:1605-1615.

21. Chiarioni G, Kim SM, Vantini I, Whitehead WE. Validation of the balloon evacuation test: reproducibility and agreement with findings from anorectal manometry and electromyography. Clin Gastroenterol Hepatol 2014;12:2049-2054.

22. Savoye-Collet C, Koning E, Dacher JN. Radiologic evaluation of pelvic floor disorders. Gastroenterol Clin North Am 2008;37:553567.

23. Lalwani N, Moshiri M, Lee JH, Bhargava P, Dighe MK. Magnetic resonance imaging of pelvic floor dysfunction. Radiol Clin North Am 2013;51:1127-1139.

24. Wald A, Bharucha AE, Cosman BC, Whitehead WE. ACG clinical guideline: management of benign anorectal disorders. Am J Gastroenterol 2014;109:1141-1157. 
25. Metcalf AM, Phillips SF, Zinsmeister AR, MacCarty RL, Beart RW, Wolff BG. Simplified assessment of segmental colonic transit. Gastroenterology 1987;92:40-47.

26. Rao SS, Kuo B, McCallum RW, et al. Investigation of colonic and whole-gut transit with wireless motility capsule and radiopaque markers in constipation. Clin Gastroenterol Hepatol 2009;7:537544.

27. Stivland T, Camilleri M, Vassallo M, et al. Scintigraphic measurement of regional gut transit in idiopathic constipation. Gastroenterology 1991;101:107-115.

28. Rao SS, Coss-Adame E, Valestin J, Mysore K. Evaluation of constipation in older adults: radioopaque markers (ROMs) versus wireless motility capsule (WMC). Arch Gerontol Geriatr 2012;55:289294.

29. Rao SS, Bharucha AE, Chiarioni G, et al. Anorectal disorders. Gastroenterology 2016;150:1430-1442.e2.

30. Halligan S, Thomas J, Bartram C. Intrarectal pressures and balloon expulsion related to evacuation proctography. Gut 1995;37:100104.

31. Suttor VP, Prott GM, Hansen RD, Kellow JE, Malcolm A. Evidence for pelvic floor dyssynergia in patients with irritable bowel syndrome. Dis Colon Rectum 2010;53:156-160.

32. Rao SS, Benninga MA, Bharucha AE, Chiarioni G, Di Lorenzo C, Whitehead WE. ANMS-ESNM position paper and consensus guidelines on biofeedback therapy for anorectal disorders. Neurogastroenterol Motil 2015;27:594-609.

33. Chiarioni G, Whitehead WE, Pezza V, Morelli A, Bassotti G. Biofeedback is superior to laxatives for normal transit constipation due to pelvic floor dyssynergia. Gastroenterology 2006;130:657664.

34. Heymen S, Scarlett Y, Jones K, Ringel Y, Drossman D, Whitehead WE. Randomized, controlled trial shows biofeedback to be superior to alternative treatments for patients with pelvic floor dyssynergia-type constipation. Dis Colon Rectum 2007;50:428-441.

35. Rao SS, Seaton K, Miller M, et al. Randomized controlled trial of biofeedback, sham feedback, and standard therapy for dyssynergic defecation. Clin Gastroenterol Hepatol 2007;5:331-338.

36. Rao SS, Valestin J, Brown CK, Zimmerman B, Schulze K. Longterm efficacy of biofeedback therapy for dyssynergic defecation: randomized controlled trial. Am J Gastroenterol 2010;105:890896.

37. Bordeianou L, Hicks CW, Kaiser AM, Alavi K, Sudan R, Wise PE. Rectal prolapse: an overview of clinical features, diagnosis, and patient-specific management strategies. J Gastrointest Surg 2014;18:1059-1069.

38. Varma M, Rafferty J, Buie WD; Standards Practice Task Force of American Society of Colon and Rectal Surgeons. Practice parameters for the management of rectal prolapse. Dis Colon Rectum 2011;54:1339-1346.

39. Glasgow SC, Birnbaum EH, Kodner IJ, Fleshman JW, Dietz DW. Preoperative anal manometry predicts continence after perineal proctectomy for rectal prolapse. Dis Colon Rectum 2006;49:1052-
1058.

40. Kaufman HS, Buller JL, Thompson JR, et al. Dynamic pelvic magnetic resonance imaging and cystocolpoproctography alter surgical management of pelvic floor disorders. Dis Colon Rectum 2001;44:1575-1583.

41. Santoro GA, Wieczorek AP, Dietz HP, et al. State of the art: an integrated approach to pelvic floor ultrasonography. Ultrasound Obstet Gynecol 2011;37:381-396.

42. Tou S, Brown SR, Malik AI, Nelson RL. Surgery for complete rectal prolapse in adults. Cochrane Database Syst Rev 2008;(4):CD001758.

43. White WM, Pickens RB, Elder RF, Firoozi F. Robotic-assisted sacrocolpopexy for pelvic organ prolapse. Urol Clin North Am 2014;41:549-557.

44. Olsen AL, Smith VJ, Bergstrom J0, Colling JC, Clark AL. Epidemiology of surgically managed pelvic organ prolapse and urinary incontinence. Obstet Gynecol 1997;89:501-506.

45. Luo J, Larson KA, Fenner DE, Ashton-Miller JA, DeLancey JO. Posterior vaginal prolapse shape and position changes at maximal Valsalva seen in 3-D MRI-based models. Int Urogynecol J 2012;23:1301-1306.

46. Shorvon PJ, McHugh S, Diamant NE, Somers S, Stevenson GW. Defecography in normal volunteers: results and implications. Gut 1989;30:1737-1749.

47. Mustain WC. Functional disorders: rectocele. Clin Colon Rectal Surg 2017;30:63-75.

48. Van Laarhoven CJ, Kamm MA, Bartram CI, Halligan S, Hawley PR, Phillips RK. Relationship between anatomic and symptomatic long-term results after rectocele repair for impaired defecation. Dis Colon Rectum 1999;42:204-210.

49. van Dam JH, Ginai AZ, Gosselink MJ, et al. Role of defecography in predicting clinical outcome of rectocele repair. Dis Colon Rectum 1997;40:201-207.

50. Prichard D0, Lee T, Parthasarathy G, Fletcher JG, Zinsmeister AR, Bharucha AE. High-resolution anorectal manometry for identifying defecatory disorders and rectal structural abnormalities in women. Clin Gastroenterol Hepatol 2017;15:412-420.

51. Yoshioka K, Matsui Y, Yamada 0, et al. Physiologic and anatomic assessment of patients with rectocele. Dis Colon Rectum 1991;34:704-708.

52. Schey R, Cromwell J, Rao SS. Medical and surgical management of pelvic floor disorders affecting defecation. Am J Gastroenterol 2012;107:1624-1633.

53. Harewood GC, Coulie B, Camilleri M, Rath-Harvey D, Pemberton $\mathrm{JH}$. Descending perineum syndrome: audit of clinical and laboratory features and outcome of pelvic floor retraining. Am J Gastroenterol 1999;94:126-130.

54. Landmann RG, Wexner SD. Paradoxical puborectalis contraction and increased perineal descent. Clin Colon Rectal Surg 2008;21:138-145.

55. Bartolo DC, Jarratt JA, Read MG, Donnelly TC, Read NW. The role of partial denervation of the puborectalis in idiopathic faecal in- 
continence. Br J Surg 1983;70:664-667.

56. Bartolo DC, Roe AM, Mortensen NJ. The relationship between perineal descent and denervation of the puborectalis in continent patients. Int J Colorectal Dis 1986;1:91-95.

57. Jorge JM, Wexner SD, Ehrenpreis ED, Nogueras JJ, Jagelman DG. Does perineal descent correlate with pudendal neuropathy? Dis Colon Rectum 1993;36:475-483.

58. Foti PV, Farina R, Riva G, et al. Pelvic floor imaging: comparison between magnetic resonance imaging and conventional defecography in studying outlet obstruction syndrome. Radiol Med 2013;118:23-39.

59. Kelvin FM, Maglinte DD, Hale DS, Benson JT. Female pelvic organ prolapse: a comparison of triphasic dynamic MR imaging and triphasic fluoroscopic cystocolpoproctography. AJR Am J Roentgenol 2000;174:81-88.

60. Chaudhry Z, Tarnay C. Descending perineum syndrome: a review of the presentation, diagnosis, and management. Int Urogynecol J 2016;27:1149-1156

61. Tjandra JJ, Fazio VW, Church JM, Lavery IC, Oakley JR, Milsom JW. Clinical conundrum of solitary rectal ulcer. Dis Colon Rectum 1992;35:227-234.

62. Edden Y, Shih SS, Wexner SD. Solitary rectal ulcer syndrome and stercoral ulcers. Gastroenterol Clin North Am 2009;38:541-545.

63. Rao SS, Ozturk R, De Ocampo S, Stessman M. Pathophysiology and role of biofeedback therapy in solitary rectal ulcer syndrome. Am J Gastroenterol 2006;101:613-618.

64. Morio 0, Meurette G, Desfourneaux V, D'Halluin PN, Bretagne JF, Siproudhis L. Anorectal physiology in solitary ulcer syndrome: a case-matched series. Dis Colon Rectum 2005;48:1917-1922.
65. Keighley MR, Shouler P. Clinical and manometric features of the solitary rectal ulcer syndrome. Dis Colon Rectum 1984;27:507512.

66. Abid S, Khawaja A, Bhimani SA, Ahmad Z, Hamid S, Jafri W. The clinical, endoscopic and histological spectrum of the solitary rectal ulcer syndrome: a single-center experience of 116 cases. BMC Gastroenterol 2012;12:72.

67. Chiang JM, Changchien CR, Chen JR. Solitary rectal ulcer syndrome: an endoscopic and histological presentation and literature review. Int J Colorectal Dis 2006;21:348-356.

68. Levine DS, Surawicz CM, Ajer TN, Dean PJ, Rubin CE. Diffuse excess mucosal collagen in rectal biopsies facilitates differential diagnosis of solitary rectal ulcer syndrome from other inflammatory bowel diseases. Dig Dis Sci 1988;33:1345-1352.

69. Marshall M, Halligan S, Fotheringham T, Bartram C, Nicholls RJ. Predictive value of internal anal sphincter thickness for diagnosis of rectal intussusception in patients with solitary rectal ulcer syndrome. Br J Surg 2002;89:1281-1285.

70. Jarrett ME, Emmanuel AV, Vaizey CJ, Kamm MA. Behavioural therapy (biofeedback) for solitary rectal ulcer syndrome improves symptoms and mucosal blood flow. Gut 2004;53:368-370.

71. Somani SK, Ghosh A, Avasthi G, Goyal R, Gupta P. Healing of a bleeding solitary rectal ulcer with multiple sessions of argon plasma. Gastrointest Endosc 2010;71:578-582.

72. Evans C, Ong E, Jones OM, Cunningham C, Lindsey I. Laparoscopic ventral rectopexy is effective for solitary rectal ulcer syndrome when associated with rectal prolapse. Colorectal Dis 2014;16:0112-0116. 